\title{
Thyroid Cancer in Children
}

$\mathbf{T}$

he American Cancer Society estimates that 67,200 new cases of thyroid cancer were diagnosed in the United States in 2013 (1). The median age at diagnosis for all patients is $50 \mathrm{y}$, with less than $2 \%$ of occurrences being in patients younger than 20 y (2). Thyroid cancer is 10 -fold more common in adolescents than in younger children. Because the expected number of adolescents (ages 15-19 y) in the United States with new diagnoses of thyroid cancer in 2014 is approximately 570 (3), we should anticipate about 625 new thyroid cancer diagnoses in children and adolescents combined, with about $90 \%$ being differentiated thyroid cancer (DTC) (4). This incidence compares with expected incidences of about 700 for neuroblastoma (3), 400 for osteosarcoma (5), and 350 for rhabdomyosarcoma (6).

\section{See page 710}

There have been major advances in the treatment results for most solid malignancies of childhood although cure rates remain suboptimal, particularly for those with advanced disease. DTC, however, has been associated with high survival rates in children for more than $30 \mathrm{y}$. Since 1975, the 5-y survival rates of adolescents with thyroid cancer have ranged from $97.5 \%$ to $99.6 \%$ (7). Only $0.1 \%$ of thyroid cancer deaths occur in patients younger than $20 \mathrm{y}$. Despite high survival rates, pediatric patients with DTC frequently present with regional cervical lymph nodal metastases and distant metastatic disease, most commonly involving the lungs. Such

Received Feb. 26, 2014; revision accepted Feb. 27, 2014.

For correspondence or reprints contact: Barry L. Shulkin, Division of Nuclear Medicine, St. Jude Children's Research Hospital, 262 Danny Thomas

Place, Mail Stop 220, Memphis, TN 38105.

E-mail: barry.shulkin@stjude.org

Published online Apr. 10, 2014.

COPYRIGHT (C) 2014 by the Society of Nuclear

Medicine and Molecular Imaging, Inc.

DOI: 10.2967/jnumed.113.136077 patients require an aggressive treatment approach consisting of total thyroidectomy and excision of all surgically accessible local-regional metastatic deposits, followed by administration of one or more courses of ${ }^{131}$ I therapy.

The Children's Oncology Group has no treatment studies for thyroid cancer (http:// www.childrensoncologygroup.org/index.php/ aboutus): considering the high survival rate of pediatric patients with DTC and the slow rate of DTC progression, which would require long follow-up intervals to assess the effect of therapeutic interventions on outcomes, it is unlikely that such studies will occur in the foreseeable future. Thus, most thyroid cancer in children is treated empirically. We therefore rely on retrospective analyses, despite their inherent limitations, to estimate the utility of therapeutic approaches. In that regard, the article of Mihailovic, Nikoletic, and Srbovan (8), published in this edition of the Journal of Nuclear Medicine, provides further information about the probability of recurrent disease and the effect of therapeutic interventions on the outcome of pediatric DTC. On the basis of a 35-y clinical experience of treating thyroid cancer at a major oncology referral center in Serbia, the authors conclude that younger age at diagnosis, relatively conservative initial surgical intervention without subsequent ${ }^{131}$ I therapy, and tumor multifocality are strong prognostic factors for recurrence.

There have been substantial changes in the management of DTC cases in the past decade. The most commonly used staging system for thyroid cancer is the TNM staging system of the American Joint Committee on Cancer/International Union against Cancer, currently in the seventh edition. American Joint Committee on Cancer guidelines classify younger patients (age $<45 \mathrm{y}$ ) as either stage I (any T, any N, M0) or II (any T, any $\mathrm{N}, \mathrm{M} 1$ ), and stages III and IV are not applicable to younger patients (9). Irrespective of tumor size, multifocality, and the extent of lymph node involvement, younger patients are classified as having stage I disease in the absence of distant metastases. The staging system predicts survival but does not capture information about the risk of recurrence, which is significantly different in patients with small intrathyroidal tumors without nodal metastases from that in young patients with large tumors and extensive lymph node involvement, although both groups are classified as having stage I disease.

To account for the increased risk of persistent and recurrent disease in patients with large tumors, aggressive histologic subtypes, and the presence of cervical lymph nodal metastases, the American Thyroid Association has developed a 3-level risk stratification system that is used with staging information to determine whether patients would benefit from ${ }^{131}$ I therapy: recommendations call for ${ }^{131} \mathrm{I}$ treatment for patients with distant metastases, gross extrathyroidal invasion, and tumors larger than $4 \mathrm{~cm}$ and for selected patients with 1- to 4-cm tumors confined to the thyroid who have documented node metastases or other high-risk features. The American Thyroid Association guidelines recommend against ${ }^{131} \mathrm{I}$ ablation in patients with unifocal or multifocal tumors smaller than $1 \mathrm{~cm}$ (microcarcinomas) without high-risk features (10). Routine use of ${ }^{131} \mathrm{I}$ administration after total thyroidectomy is no longer recommended because this approach has been challenged by evidence that remnant ablation does not improve survival in low-risk patients (1116). In this context, it has become important to determine which patients will benefit from selective administration of ${ }^{131} \mathrm{I}$ postoperatively. In addition to histopathology information provided in the surgical pathology report, the diagnostic information obtained during preablation scans with ${ }^{123} \mathrm{I}$ or ${ }^{131} \mathrm{I}$ can serve to identify patients with unsuspected regional and distant metastases and to define the target of ${ }^{131}$ I therapy. When high-dose ${ }^{131}$ I therapy is necessary for treatment of distant metastatic disease, dosimetry calculations can be performed on the basis of percentage wholebody retention at $48 \mathrm{~h}$, using the tracer dose of ${ }^{123} \mathrm{I}$ or ${ }^{131} \mathrm{I}$ that was used for preablation imaging.

Controversy still surrounds the issue of stunning by the diagnostic scan dose (defined as a reduction of ${ }^{131} \mathrm{I}$ uptake seen on posttherapy scans as compared with preablation scans and interpreted as potentially causing a decreased effect of the subsequent therapy dose when administered after 
a ${ }^{131}$ I preablation scan), as more recent investigations examining the issue have found little or no evidence of stunning (17-21). The contemporary view is that the importance of stunning was overemphasized, that stunning appears not to be a problem at doses of less than $74 \mathrm{MBq}(2$ $\mathrm{mCi}$ ) of ${ }^{131} \mathrm{I}$ when ${ }^{131} \mathrm{I}$ therapy is administered within $72 \mathrm{~h}$ of the diagnostic ${ }^{131} \mathrm{I}$ dose, and that stunning may be related to a true cytocidal effect of the high ${ }^{131} \mathrm{I}$ diagnostic doses (185-370 MBq [5-10 mCi]) used in the past (22-24). In this context, preablation imaging can be used to evaluate the presence of regional and distant metastases as part of staging and risk stratification and to inform decisions about the indication for ${ }^{131} \mathrm{I}$ therapy and the prescribed ${ }^{131} \mathrm{I}$ activity for treatment.

Assessing outcomes of ${ }^{131} \mathrm{I}$ therapy in patients with documented iodine-avid regional and distant metastatic disease is particularly relevant. The current study by Mihailovic et al. examines the outcome of 53 patients aged 7-20 y with thyroid cancer who were treated at a large referral center in Serbia. Although the extent of surgery varied among hospitals, the approach to ${ }^{131}$ I treatment was uniform. Thyroxin was withheld for $4 \mathrm{wk}$, resulting in thyroid-stimulating hormone elevation of at least $30 \mathrm{mU} / \mathrm{L}$ (written communication, Jasna Mihailovic, February 9, 2014). A diagnostic study preceded the treatment (written communication, Jasna Mihailovic, February 9, 2014). Therapy doses for postpubertal children ranged from 3,700 to $7,400 \mathrm{MBq}(100-200 \mathrm{mCi})$ of ${ }^{131} \mathrm{I}$. Posttherapy ${ }^{131}$ I scintigraphy was performed at 72 h. Follow-up was frequent and comprehensive. Thyroglobulin and thyroid-stimulating hormone levels were monitored every 3 mo in the first year after ${ }^{131}$ I treatment, then every $6 \mathrm{mo}$ for $5 \mathrm{y}$, and then yearly. Follow-up diagnostic ${ }^{131}$ I whole-body studies (148 MBq [4 mCi]) were performed approximately $1 \mathrm{y}$ after the first ${ }^{131} \mathrm{I}$ ablation. Ablation was considered successful if there was no abnormal uptake of ${ }^{131} \mathrm{I}$ and if thyroglobulin levels were undetectable during the thyroid hormone withdrawal period.

The few patients who were not initially treated with ${ }^{131} \mathrm{I}$ each had recurrent disease. Because all reported patients had received ${ }^{131} \mathrm{I}$ therapy at some point during the course of treatment, it is unclear how many patients in the country did not have ${ }^{131}$ I treatment for thyroid cancer. Thus, there may have been a selection bias toward patients with presumably higher-risk disease, although the study reports on DTC management between 1977 and 2012, which includes a period in which routine rather than selective ${ }^{131}$ I ablation was commonly used.

Of the 51 patients, 29 received only a single dose of ${ }^{131} \mathrm{I}$ and experienced a long-term remission and likely cure, but the remaining 22 patients required repeated courses of ${ }^{131}$ I therapy. During long-term follow-up, 11 patients (22\%) experienced recurrent disease, with a median time to recurrence of $52 \mathrm{mo}$; however, in 2 patients the recurrences were late. Even in those patients with relapse, outcomes were favorable, as nearly all experienced complete remission. In up to $30 \mathrm{y}$ of observation, no effects on subsequent fertility and pregnancy and no secondary malignancies were observed. The authors conclude that, in addition to age and tumor multifocality, the type of initial treatment (completeness of surgical resection and whether postoperative ${ }^{131}$ I therapy was received) is predictive for recurrence risk: the group of patients treated with total thyroidectomy and postoperative ${ }^{131}$ I had a lower risk for recurrent disease than did the other groups.

The results must be understood in the context of the high incidence of regional and distant metastases in the cohort of patients presented in the report by Mihailovic et al. $69 \%$ of patients had lymph node metastases, and $14 \%$ had distant pulmonary metastatic disease at presentation (8). Detecting residual iodine-avid lymph node metastatic disease after surgery and the presence of distant pulmonary metastases will clearly direct management toward postoperative ${ }^{131} \mathrm{I}$ administration as opposed to management without ${ }^{131}$ I ablation. In this context, using preablation scans allows recommended staging and risk stratification of thyroid cancer cases before management decisions. The advantages include the delivery of appropriately higher activities at the first ${ }^{131}$ I therapy for patients with high-risk disease, when the iodine-concentrating ability of the tumor is presumably highest, and reduction or omission of activity prescribed for radioablation for thyroid remnants. In fact, it is specifically those patients in whom ablation is omitted who may benefit from a postoperative diagnostic scan to exclude the presence of regional and distant metastases.

Imaging technology has significantly evolved over the past $10 \mathrm{y}$, and the image quality of current SPECT/CT systems is substantially superior to that of earlier $\gamma$ cameras, permitting high-quality diagnostic imaging with tracer doses of ${ }^{131} \mathrm{I}$ : this progress has been achieved by improving the spatial and contrast resolution of modern SPECT/CT cameras and applying scatter rejection, iterative reconstruction, and CT-based attenuation correction algorithms for SPECT. The additional radiation exposure from the tracer radioiodine dose (approximately $4 \mathrm{mSv}$ for $37 \mathrm{MBq}[1 \mathrm{mCi}]$ of $\left.{ }^{131} \mathrm{I}\right)$ and CT component of the study (1-4 $\mathrm{mSv}$ with each acquisition) (25) is very low compared with the effective absorbed radiation dose from ${ }^{131} \mathrm{I}$ therapy (400-600 $\mathrm{mSv}$ for $3,700-5,550 \mathrm{MBq}$ [100-150 $\mathrm{mCi}]$ of $\left.{ }^{131} \mathrm{I}\right)$. In this context, all information available from clinical or surgical pathology and diagnostic imaging should be used in deciding the risks and benefits of selective use of ${ }^{131}$ I therapy. The study by Mihailovic et al. (8) provides evidence about the effect of ${ }^{131}$ I therapy on pediatric DTC outcomes, and the selection of patients who will most benefit from this treatment remains an important task for all physicians prescribing ${ }^{131}$ I therapy.

\section{DISCLOSURE}

No potential conflict of interest relevant to this article was reported.

\section{ACKNOWLEDGMENT}

We thank Cherise Guess, PhD, Scientific Editing, St. Jude Children's Research Hospital, for expertise in composing the manuscript.

\section{Anca M. Avram \\ University of Michigan \\ Ann Arbor, Michigan}

Barry L. Shulkin

St. Jude Children's Research Hospital Memphis, Tennessee

\section{REFERENCES}

1. Thyroid cancer overview. http://www.cancer.org/ cancer/thyroidcancer/overviewguide/thyroid-canceroverview-key-statistics. American Cancer Society website. Published May 9, 2013. Updated February 11, 2014. Accessed March 3, 2014.

2. Waguespack SG, Francis G. Initial management and follow-up of differentiated thyroid cancer in children. J Natl Compr Canc Netw. 2010;8:12891300.

3. Ward E, Desantis C, Robbins A, Kohler B, Jemal A. Childhood and adolescent cancer statistics, 2014. CA Cancer J Clin. January 31, 2014 [Epub ahead of print].

4. Waguespack SG, Bauer AJ, Huh W, Ying AK. Endocrine tumors. In Pizzo PA, Poplack DG, eds. Principles and Practice of Pediatric Oncology. Philadelphia, PA: Lippincott Williams and Wilkins; 2011:1068-1097. 
5. Gorlick R, Bielack S, Teot L, Meyer J, Randall RL, Marina N. Osteosarcoma: biology, diagnosis, treatment, and remaining challenges. In Pizzo PA, Poplack DG, eds. Principles and Practice of Pediatric Oncology. Philadelphia, PA: Lippincott Williams and Wilkins; 2011:1015-1044.

6. Wexler LH, Meyer WH, Helman LJ. Rhabdomyosarcoma. In Pizzo PA, Poplack DG, eds. Principles and Practice of Pediatric Oncology. Philadelphia, PA: Lippincott Williams and Wilkins; 2011:923-953.

7. Howlader N, Noone AM, Krapcho M, et al, eds. SEER cancer statistics review (CSR) 1975-2010. National Cancer Institute website. http://seer. cancer.gov/csr/1975_2010/. Published April 2013. Updated June 14, 2013. Accessed March 3, 2014.

8. Mihailovic J, Nikoletic K, Srbovan D. Recurrent disease in juvenile differentiated thyroid carcinoma: prognostic factors, treatment, and outcome. $\mathrm{J} \mathrm{Nucl}$ Med. 2014;55:710-717.

9. Edge S, Byrd DR, Compton CC, Fritz AG, Greene FL, Trotti A, eds. AJCC Cancer Staging Manual. 7th ed. New York, NY: Springer; 2010.

10. Cooper DS, Doherty GM, Haugen BR, et al; American Thyroid Association (ATA) Guidelines Taskforce on Thyroid Nodules and Differentiated Thyroid Cancer. Revised American Thyroid Association management guidelines for patients with thyroid nodules and differentiated thyroid cancer. Thyroid. 2009;19:1167-1214.
11. Hay ID. Selective use of radioactive iodine in the postoperative management of patients with papillary and follicular thyroid carcinoma. J Surg Oncol. 2006; 94:692-700.

12. Hay ID, Thompson GB, Grant CS, et al. Papillary thyroid carcinoma managed at the Mayo Clinic during six decades (1940-1999): temporal trends in initial therapy and long-term outcome in 2444 consecutively treated patients. World J Surg. 2002;26:879-885.

13. Jonklaas J, Cooper DS, Ain KB, et al. Radioiodine therapy in patients with stage I differentiated thyroid cancer. Thyroid. 2010;20:1423-1424.

14. Jonklaas J, Sarlis NJ, Litofsky D, et al. Outcomes of patients with differentiated thyroid carcinoma following initial therapy. Thyroid. 2006;16:12291242.

15. Podnos YD, Smith DD, Wagman LD, Ellenhorn JD. Survival in patients with papillary thyroid cancer is not affected by the use of radioactive isotope. $J$ Surg Oncol. 2007;96:3-7.

16. Sacks W, Fung $\mathrm{CH}$, Chang JT, Waxman A, Braunstein GD. The effectiveness of radioactive iodine for treatment of low-risk thyroid cancer: a systematic analysis of the peer-reviewed literature from 1966 to April 2008. Thyroid. 2010;20:12351245.

17. Morris LF, Waxman AD, Braunstein GD. The nonimpact of thyroid stunning: remnant ablation rates in ${ }^{131} \mathrm{I}$-scanned and nonscanned individuals. J Clin Endocrinol Metab. 2001;86:3507-3511.

18. McDougall IR. $74 \mathrm{MBq}$ radioiodine ${ }^{131}$ I does not prevent uptake of therapeutic doses of ${ }^{131}$ I (i.e. it does not cause stunning) in differentiated thyroid cancer. Nucl Med Commun. 1997;18:505-512.

19. Cholewinski SP, Yoo KS, Klieger PS, O'Mara RE. Absence of thyroid stunning after diagnostic whole-body scanning with $185 \mathrm{MBq}{ }^{131} \mathrm{I}$. $J$ Nucl Med. 2000;41:1198-1202.

20. Karam M, Gianoukakis A, Feustel PJ, Cheema A, Postal ES, Cooper JA. Influence of diagnostic and therapeutic doses on thyroid remnant ablation rates. Nucl Med Commun. 2003;24:489-495.

21. Rosário PW, Barroso AL, Rezende LL, et al. $5 \mathrm{mCi}$ pretreatment scanning does not cause stunning when the ablative dose is administered within 72 hours. Arq Bras Endocrinol Metabol. 2005;49:420-424.

22. Sisson JC, Avram AM, Lawson SA, Gauger PG, Doherty GM. The so-called stunning of thyroid tissue. J Nucl Med. 2006;47:1406-1412.

23. Silberstein EB. Comparison of outcomes after ${ }^{123} \mathrm{I}$ versus ${ }^{131} \mathrm{I}$ preablation imaging before radioiodine ablation in differentiated thyroid carcinoma. $\mathrm{J} \mathrm{Nucl}$ Med. 2007;48:1043-1046.

24. McDougall IR, Iagaru A. Thyroid stunning: fact or fiction? Semin Nucl Med. 2011;41:105-112.

25. Buck AK, Nekolla SG, Ziegler SI, et al. SPECT/CT. J Nucl Med. 2008;49:1305-1319. 